\title{
Increased Single Strand Breaks in DNA of Lymphocytes from Diabetic Subjects
}

\author{
Mara Lorenzi, Dominic F. Montisano, Silva Toledo, and Han-Chi Helen Wong \\ Department of Medicine, Division of Endocrinology and Metabolism, University of California, San Diego, San Diego, California 92103
}

\begin{abstract}
Certain aspects of the chronic complications of diabetes suggest that, with time, the abnormal metabolic milieu leads to irreversible changes in some cell populations. Since we have previously observed that high glucose concentrations induce an increase in single strand breaks in the DNA of cultured human endothelial cells, we have investigated whether the same abnormality occurs in cells derived from the in vivo diabetic environment. Peripheral blood lymphocytes obtained from 21 type I diabetic patients and age- and sex-matched controls were tested for rate of unwinding in alkali (a measure of DNA single strand breaks). The patients were subdivided into two groups on the basis of glycohemoglobin values above or below $9 \%$. The group with glycohemoglobin values of $12.9 \pm 2.4 \%$ (mean \pm SD), but not the group with glycohemoglobin values of $7.4 \pm 1.5 \%$, showed accelerated unwinding of lymphocyte DNA when compared to controls $(P<0.01)$. These studies suggest that poorly controlled diabetes may result in DNA lesions, whose impact on long-term complications deserves to be investigated.
\end{abstract}

\section{Introduction}

A number of aspects of the human and experimental pathology of diabetes mellitus suggests that the abnormal metabolic milieu so impacts with time on cellular function as to eventually lead to lethal or irreversible changes. Complete disappearance of vascular endothelial cells, cells that are normally capable of turnover and replication in response to injury, is a common finding in capillaries of the retina (1) and lower extremities (2) of longterm diabetic patients. Even prolonged near-normalization of the metabolic status fails, not just to correct, but to arrest the progression of advanced vascular abnormalities $(3,4)$. When transported to the in vitro environment, fibroblasts explanted from diabetic patients manifest a decreased replicative life-span (5) and vascular endothelial cells derived from genetically diabetic animals exhibit abnormal insulin receptors and proliferative delay (6).

The carry over of disturbed biologic functions in the neutral in vitro environment by cells undergoing division suggests that events that took place in vivo have led to some irreversible change in cell physiology. Vracko has proposed (5) that the increased

Address reprint requests to Dr. Lorenzi, UCSD Medical Center H-811C, 225 Dickinson Street, San Diego, CA 92103.

Received for publication 2 September 1986.

J. Clin. Invest.

(C) The American Society for Clinical Investigation, Inc. 0021-9738/87/02/0653/04 \$1.00

Volume 79, February 1987, 653-656 death rate of diabetic cells in vivo and their accelerated senescence in vitro may be a consequence of their accelerated turnover, in turn triggered by an excessive vulnerability to injury. An alternative or complementary hypothesis could be that some of the injuries inflicted by the diabetic environment involve cellular DNA and thus result in self-perpetuating changes, varyingly tolerated by different cell types.

In previous work we had demonstrated that prolonged exposure of human endothelial cells to high glucose concentrations in vitro results, together with other abnormalities (7), in an increased number of DNA single strand breaks (8). We have now sought to determine whether this type of DNA lesion is detectable in cells directly derived from the abnormal in vivo diabetic environment and not subjected to in vitro manipulations. For this investigation human circulating lymphocytes appeared especially suitable: they are easily accessible, many of them are very longlived (9) and thus potentially vulnerable to cumulative changes, and in diabetic patients they manifest a variety of abnormalities (10-14) which, if of unclear clinical importance (10), document that these cells are bystander targets of the deranged metabolic environment.

\section{Methods}

Patients. The studies were approved by the Committee on Human Studies of the University of California at San Diego (UCSD). 21 type I, insulindependent diabetic patients were recruited during their regular clinic visits at the UCSD Diabetes Center. Criteria for exclusion from the study were presence of any other systemic illness in addition to diabetes, presence of active intercurrent infection, serum creatinine level $>1.5 \mathrm{mg} /$ $\mathrm{dl}$, treatment with medications other than insulin, thyroid, and birth control pills. From each patient who had volunteered to participate in the study $20 \mathrm{ml}$ of blood was obtained for isolation of mononuclear cells and determination of blood glucose (Chemstrips bG read in Accu-Check Meter, Bio-Dynamics; Indianapolis, IN) and glycohemoglobin. Glycohemoglobin levels (normal range 5.3-7.5\%) were measured by boronate affinity chromatography (Glycotest, Pierce Chemical Co., Rockford, IL). After obtaining informed consent from each patient, a sex- and agematched nondiabetic control was recruited among the hospital staff. Criteria for exclusion were presence of any systemic illness and medications other than thyroid and birth control pills. Matching for age was within $2 \mathrm{yr}$ of the respective diabetic proband.

Isolation of lymphocytes. All blood specimens were obtained between 7:30 and 10:30 a.m. and within $1 \mathrm{~h}$ prior to isolation of lymphocytes. $18 \mathrm{ml}$ of blood drawn in vacutainer EDTA tubes (Becton Dickinson, Rutherford, NJ) were mixed with $30 \mathrm{ml}$ of Hanks' balanced salt solution (HBSS, Irvine Scientific, Santa Ana, CA) at room temperature. Each 8 $\mathrm{ml}$ of the diluted blood was layered onto $3 \mathrm{ml}$ of Histopaque 1077 (Sigma Chemical Co., St. Louis, MO) in a $15-\mathrm{ml}$ conical centrifuge tube. The tubes were centrifuged at $400 \mathrm{~g}$ for $30 \mathrm{~min}$ at room temperature. The mononuclear cell band was carefully aspirated from each tube, mixed with $10 \mathrm{ml}$ of HBSS and centrifuged at $250 \mathrm{~g}$ for $10 \mathrm{~min}$ at room temperature. After an additional wash in HBSS the cells were pooled for 
Table I. Clinical Characteristics of Diabetic Patients and Nondiabetic Controls

\begin{tabular}{|c|c|c|c|c|c|c|c|}
\hline & \multicolumn{5}{|l|}{ Mean \pm SD } & \multirow{2}{*}{$\begin{array}{l}\text { Proliferative } \\
\text { retinopathy }\end{array}$} & \multirow[b]{2}{*}{$\mathbf{M} / \mathbf{F}^{*}$} \\
\hline & GlycoHb & Blood glucose & Insulin dose & Age & DM duration & & \\
\hline & $\%$ & $m g / d l$ & $U / d$ & $y r$ & $y r$ & & \\
\hline DM group 1 & $12.9 \pm 2.4^{\ddagger}$ & $231 \pm 133$ & $45.5 \pm 19.8$ & $31.3 \pm 6.8$ & $19.0 \pm 10$ & $4 / 11$ & $5 / 6$ \\
\hline Controls & & & & $31.9 \pm 7.1$ & & & $5 / 6$ \\
\hline DM group 2 & $7.4 \pm 1.5$ & $162 \pm 112$ & $46.2 \pm 16.1$ & $31.5 \pm 6.9$ & $14.5 \pm 6.8$ & $2 / 10$ & $5 / 5$ \\
\hline Controls & & & & $31.3 \pm 6.5$ & & & $5 / 5$ \\
\hline
\end{tabular}

* Number of males/number of females. ${ }^{\ddagger} P<0.0001$ vs. DM group 2.

counting (hemocytometer), pelleted once more by centrifugation and resuspended in the desired volume of buffer $(0.25 \mathrm{M}$ mesoinositol, 10 $\mathrm{mM}$ sodium phosphate, $1 \mathrm{mM} \mathrm{MgCl}_{2}, \mathrm{pH} \mathrm{7.2)}$ for use in the DNA unwinding assay.

A slide for differential cell count was made from the above cell suspension, allowed to air dry, dipped in methanol, and stained with Wright's stain (Camco Quick Stain, Âmerican Scientific Products, McGaw Park, IL). The isolated cells were consistently over $95 \%$ mononuclear cells. In most preparations cell viability was also determined by trypan blue exclusion. Viability was over $95 \%$ and did not differ between diabetic and control lymphocytes.

DNA unwinding assay. This assay, originally described by Birnboim and Jevcak (15) and validated by several investigators (16-18) including ourselves (8), detects the presence of single strand breaks in DNA by monitoring the unwinding of DNA exposed to alkali. Unwinding is detected by measuring the fluorescence due to the binding of ethidium bromide to residual double-stranded DNA. The percentage of double stranded DNA remaining after different times of exposure to alkali is calculated by the equation (15): Percent double stranded DNA = (sample fluorescence - background fluorescence)/(total fluorescence - background fluorescence).

Aliquots of the lymphocyte suspension $\left(5 \times 10^{5}\right.$ cells) were distributed in triplicate into three sets of glass tubes: in one set (total double-stranded DNA) unwinding in alkali was prevented; in the second (background) unwinding was maximized by sonication; and in the third (experimental sample) unwinding in alkali was allowed to occur as a function of time. Reagents and procedures employed for the assay were as previously described (8).

In preliminary studies we established the intraassay and interassay coefficient of variation (CV). ${ }^{1}$ In three experiments the intraassay CV (two to three sets of lymphocytes from the same subject studied in the same assay) was $0.05,1.0$, and $1.9 \%$. The interassay CV (lymphocytes from the same subjects studied in different assays on different days) was 8.7, 9.1, and 9.9\%, respectively, in three experiments. These data indicated the desirability of testing the lymphocytes of each individual diabetic patient in the same assay as the respective sex-and age-matched control. Typically we tested one diabetic patient and his or her respective control each day; occasionally two pairs were tested in the same day and assay.

Analysis of the data. The values for percent double stranded DNA remaining at the various time points after alkaline elution were compared (analysis of variance) for: ( $a$ ) the total group of diabetic patients and nondiabetic controls, and $(b)$ the group of diabetic patients with glycohemoglobin values $>9 \%$ and their respective controls. The two groups of diabetic patients (glycohemoglobin value greater or lesser than $9 \%$ ) were compared by two-tailed $t$ test (unpaired analysis) for blood glucose value, daily insulin dose, age, and duration of diabetes.

\section{Results}

We had originally compared DNA unwinding for the total group of diabetic patients versus controls and found a statistically sig-

1. Abbreviations used in this paper: $\mathrm{CV}$, coefficient of variation. nificant difference at $P=0.03$. From observation of the data it was clear that the patients with the highest glycohemoglobin values were the ones mostly contributing to the statistical significance. We thus subdivided the patients into two groups: those with glycohemoglobin values $>9 \%$ (group 1) and those with glycohemoglobin values $<9 \%$ (group 2). The $9 \%$ cut-off point was chosen on the basis of suggestion from personal experience and published reports (19) that glycohemoglobin values of $9 \%$ or less are a realistic and reasonable goal for blood glucose control in insulin-dependent diabetic patients. Because of the previously observed interassay coefficient of variation for the DNA unwinding assay, each group of diabetic patients was compared with its respective group of nondiabetic controls. The clinical characteristics of diabetic patients and respective controls are summarized in Table I. The two groups were perfectly homogeneous for number, sex distribution, and age. Blood glucose values tended to be higher and duration of diabetes longer in the group of patients with elevated glycohemoglobin, but the difference did not achieve statistical significance. Of the 21 patients, 1 was on thyroid replacement and 1 was a smoker; of the 21 controls, 1 was on oral contraceptives and 1 was a smoker.

When compared to the respective control group, the rate of disappearance of double stranded DNA-indicative of an increased number of single strand breaks-was significantly $(P$ $<0.01$ ) accelerated in the group of patients with elevated glycohemoglobin (Fig. 1). In contrast, the unwinding of DNA from lymphocytes of group 2 patients (normal glycohemoglobin) was indistinguishable from that of the respective control group.

The same pattern was apparent when analyzing, instead of the curves of percent residual double-stranded DNA, the decrements in fluorometric readings (total undisturbed DNA

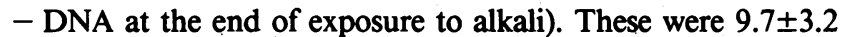
in the patients with high glycohemoglobin, $5.9 \pm 1.6$ in the patients with normal glycohemoglobin and 7.0 \pm 2.2 in the combined control group. By analysis of variance, these values were significantly different $(P<0.01)$ and by multiple range testing the high glycohemoglobin group differed $(P<0.01)$ from both the normal glycohemoglobin group and the nondiabetic controls. There was no statistically significant difference between the latter two groups.

5 of the 11 patients with elevated glycohemoglobin had values of residual double stranded DNA at 90 min (and decrements in fluorometric readings) below the mean $\pm 1 \mathrm{SD}$ of the nondiabetic controls.

\section{Discussion}

Although the clinical (1-4) and experimental $(5,6)$ observations that had prompted this investigation are compatible with the 


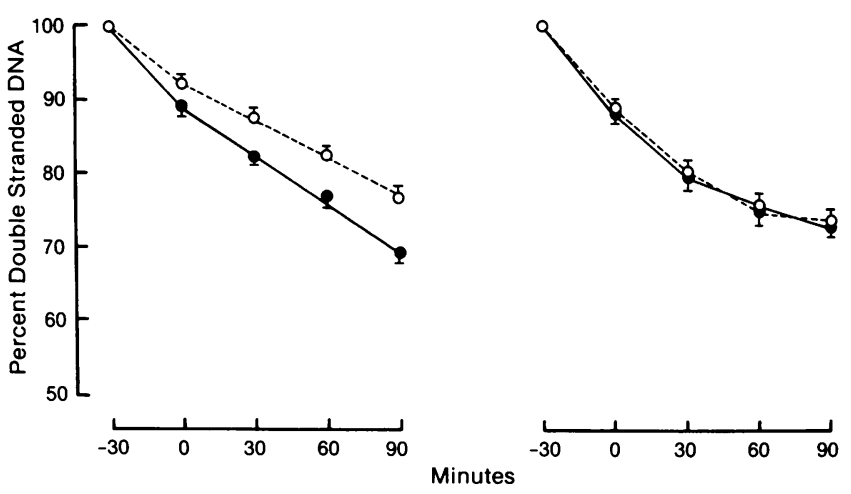

Figure 1. Kinetics of unwinding of DNA from lymphocytes of control (open circle) and diabetic subjects (solid circle) with glycohemoglobin values of $12.9 \pm 2.4 \%$ (left panel, 11 subjects) or glycohemoglobin of $7.4 \pm 1.5 \%$ (right panel, 10 subjects). $5 \times 10^{5}$ cells were used in triplicate for each time point in each assay. Cells were lysed and exposed to alkali for the indicated length of time. Exposure to alkali was at $0^{\circ} \mathrm{C}$ for the first $30 \mathrm{~min}$ and at $15^{\circ} \mathrm{C}$ thereafter. The percent doublestranded DNA was calculated as described in Methods. The data represent the mean \pm SEM of the observed values. The difference between lymphocytes of high glycohemoglobin patients and nondiabetic controls was highly significant $(P<0.01)$.

concept that the diabetic state may affect information molecules, perhaps irreversibly, the finding that DNA obtained from lymphocytes of poorly controlled diabetic patients manifest abnormal physical characteristics remains quite provocative.

The methodology employed for the study of DNA single strand breaks has been previously validated in multiple systems $(8,15-18)$. Within the same assay, the technique can reproducibly detect (15) damage induced by radiation doses as low as 5 rad (the permissible yearly exposure for radiation workers). The values for residual double stranded DNA we observed in lymphocytes from nondiabetic individuals are in perfect agreement with those previously reported for total white cell preparations (15).

If we take as definition of normal values those that fall within \pm 2 or 3 SD of the mean of a Gaussian distribution, then none of the diabetic patients had an abnormal pattern of DNA unwinding. It should, however, be considered that DNA single strand breaks are repairable lesions and that any increased extent of damage in the DNA of cells from diabetic patients must be compatible with the course of the disease, which is a long-term degenerative process, not a rapidly progressive neoplastic pathology. Thus, the differences to be expected between patients and controls were likely to be of small magnitude, and the fact that they were very consistent and achieved large statistical significance suggests that they were real, and perhaps of biologic importance. That the accelerated rate of unwinding of DNA of lymphocytes from diabetic patients may reflect events other than DNA damage, for example a greater transcriptional activity (in response to the antigenic challenge of exogenous insulin), is made unlikely by the fact that the group of patients with normal glycohemoglobin had a pattern of DNA unwinding superimposable to that of controls.

The clustering of increased DNA unwinding among the patients with high glycohemoglobin, in concert with our previous observation of similarly accelerated DNA unwinding in human endothelial cells exposed to high glucose in vitro (8), suggest that high ambient glucose may be an agent of the abnormality. Whether the increased number of single strand breaks represents a consequence of defective DNA repair synthesis and ligation or accelerated rate of breaks formation cannot be established at this time. However, the observation that nucleic acids modified in vitro by reducing sugars manifest functional abnormalities and strand scission (20), and preliminary data indicating that the high glucose-induced DNA damage in endothelial cells can be corrected by addition of antioxidants to the medium suggest that high ambient glucose may have, directly or indirectly, a clastogenic potential.

This is not the first time that DNA abnormalities have been observed in diabetic subjects. A significantly increased frequency of chromatid and chromosome exchange aberrations has been reported in the lymphocytes of patients undergoing treatment with sulfonylureas (21). This was taken as evidence of possible mutagenic activity of these drugs, but the possibility could not be ruled out that the diabetic state itself might be a contributory factor. The present study, in which no drugs were involved, would lend support to the latter interpretation. Chromosomal damage and other DNA abnormalities have been reported in aging tissues (22-24) and such abnormalities in lymphocytes from old human donors are associated with an impaired proliferative response to mitogens (22), which has also been reported for lymphocytes from diabetic subjects $(10,13)$. The association of DNA damage with impaired DNA synthesis is an established fact (25).

Although single strand breaks can be repaired, the occurrence of DNA damage can lead to additional types of DNA abnormalities $(25,26)$, especially prominent in replicating cells $(25$, 27). The studies presented here propose a number of questions to be addressed toward hopefully a better understanding of the long-term complications of diabetes.

\section{Acknowledgments}

We are grateful to Dr. E. R. Arquilla for helpful discussions and to Mrs. L. Shull for editorial assistance.

Supported by grants from the Juvenile Diabetes Foundation, The American Heart Association (California Chapter), and the Diabetes Research and Education Foundation.

\section{References}

1. Kohner, E. M., and P. Henkind. 1970. Correlation of fluorescein angiogram and retinal digest in diabetic retinopathy. Am. J. Ophthalmol. 69:403-414.

2. Tilton, R. G., A. M. Faller, J. K. Burkhardt, P. L. Hoffmann, C. Kilo, and J. R. Williamson. 1985. Pericyte degeneration and acellular capillaries are increased in the feet of human diabetic patients. Diabetologia. 28:895-900.

3. Viberti, G. C., R. W. Bilous, D. Mackintosh, J. J. Bending, and $H$. Keen. 1983. Long term correction of hyperglycaemia and progression of renal failure in insulin dependent diabetes. Br. Med. J. 286:598-602.

4. Lauritzen, T., K. Frost-Larsen, H.-W. Larsen, T. Deckert, and the Steno Study Group. 1985. Two-year experience with continuous subcutaneous insulin infusion in relation to retinopathy and neuropathy. Diabetes. 34(Suppl. 3):74-79.

5. Vracko, R., and E. P. Benditt. 1975. Restricted replicative lifespan of diabetic fibroblasts in vitro: its relation to microangiopathy. Fed. Proc. 34:68-70.

6. Kwok, C. F., N. Banskota, S. Reddy, and G. L. King. 1986. Iden- 
tification of specific biochemical and growth differences between diabetic and normal capillary endothelial cells. Diabetes. 35(Suppl. 1):40 A.

7. Lorenzi, M., E. Cagliero, and S. Toledo. 1985. Glucose toxicity for human endothelial cells in culture. Diabetes. 34:621-627.

8. Lorenzi, M., D. F. Montisano, S. Toledo, and A. Barrieux. 1986. High glucose induces DNA damage in cultured human endothelial cells. J. Clin. Invest. 77:322-325.

9. Craddock, C. G., R. L. Longmire, and R. McMillan. 1977. Cellular kinetics of lymphocytes and plasma cells. In Hematology. W. J. Williams, E. Butler, A. J. Erslev, and R. W. Rundles, editors. McGraw-Hill Co., New York. 902-919.

10. Jones, R. L., and C. M. Peterson. 1981. Hematologic alterations in diabetes mellitus. Am. J. Med. 70:339-352.

11. Brody, J. I., and K. Merlie. 1970. Metabolic and biosynthetic features of lymphocytes from patients with diabetes mellitus: similarities to lymphocytes in chronic lymphocytic leukaemia. Br. J. Haematol. 19: 193-201.

12. Casey, J. I., B. J. Heeter, and K. A. Klyshevich. 1977. Impaired response of lymphocytes of diabetic subjects to antigen of Staphylococcus aureus. J. Infect. Dis. 136:495-501.

13. Glassman, A. B., J. H. Lindsay, Jr., C. E. Bennett, and E. R. Hodges, Jr. 1981. Effects of insulin on phytohemagglutinin-P, concanavalin-A, and pokeweed mitogen in diabetic and nondiabetic lymphocytes. Ann. Clin. Lab. Sci. 11:9-14.

14. Cheung, H. C., E. C. Almira, P. C. Kansal, and W. J. Reddy. 1980. A membrane abnormality in lymphocytes from diabetic subjects. Endocrinol. Res. Commun. 7:145-156.

15. Birnboim, H. C., and J. J. Jevcak. 1981. Fluorometric method for rapid detection of DNA strand breaks in human white blood cells produced by low doses of radiation. Cancer Res. 41:1889-1892.

16. Singh, N., G. Poirier, and P. Cerutti. 1985. Tumor promoter phorbol-12-myristate-13-acetate induces poly ADP-ribosylation in human monocytes. Biochem. Biophys. Res. Commun. 126:1208-1214.

17. Seto, S., C. J. Carrera, M. Kubota, D. B. Wasson, and D. A. Carson. 1985. Mechanism of deoxyadenosine and 2-chlorodeoxyaden- osine toxicity to nondividing human lymphocytes. J. Clin. Invest. 75: 377-383.

18. Schraufstatter, I. U., D. B. Hinshaw, P. A. Hyslop, R. G. Spragg, and C. G. Cochrane. 1986. Oxidant injury of cells. J. Clin. Invest. 77: 1312-1320.

19. Goldstein, D. E., K. M. Parker, J. D. England, J. E. England, Jr., H.-M. Wiedmeyer, S. S. Rawlings, R. Hess, R. R. Little, J. F. Simonds, and R. P. Breyfogle. 1982. Clinical application of glycosylated hemoglobin measurements. Diabetes. 31(Suppl. 3):70-78.

20. Bucala, R., P. Model, and A. Cerami. 1984. Modification of DNA by reducing sugars: a possible mechanism for nucleic acid aging and age-related dysfunction in gene expression. Proc. Natl. Acad. Sci. USA. 81:105-109.

21. Watson, W. A. F., J. C. Petrie, D. B. Galloway, I. Bullock, and J. C. Gilbert. 1976. In vivo cytogenetic activity of sulphonylurea drugs in man. Mutation Res. 38:71-80.

22. Staiano-Coico, L., Z. Darzynkiewicz, J. M. Hefton, R. Dutkowski, G. J. Darlington, and M. E. Weksler. 1983. Increased sensitivity of lymphocytes from people over 65 to cell cycle arrest and chromosomal damage. Science (Wash. DC). 219:1335-1337.

23. Shmookler Reis, R. J., C. K. Lumpkin, Jr., J. R. McGill, K. T. Riabowol, and S. Goldstein. 1983. Extrachromosomal circular copies of an 'inter-Alu' unstable sequence in human DNA are amplified during in vitro and in vivo ageing. Nature (Lond.). 301:394-398.

24. Price, G. B., S. P. Modak, and T. Makinodan. 1971. Age-associated changes in the DNA of mouse tissue. Science (Wash. DC). 171: 917-920.

25. Friedberg, E. C. 1985. DNA Repair. W. H. Freeman and Co., San Francisco, CA. 459-504.

26. Stark, G. R., and G. M. Wahl. 1984. Gene amplification. Annu. Rev. Biochem. 53:447-491.

27. Schimke, R. T., S. W. Sherwood, A. B. Hill, and R. N. Johnston. 1986. Overreplication and recombination of DNA in higher eukaryotes. Potential consequences and biological implications. Proc. Natl. Acad. Sci. USA. 83:2157-2161. 